\title{
A Study on the New Compilation of College English Learning Materials Based on Big Data in China
}

\author{
Mao Feng' (D), Li Quan² (iD), Wu Biyu ${ }^{3}$ (D) $ه$ \\ ${ }^{12}$ Associate Professor of School of Languages, Shanghai University of International Business and Economics, Shanghai, China \\ ${ }^{3}$ Professor of School of Foreign Languages, East China University of Science and Technology, Shanghai, China
}

$\square$ Corresponding Author: Wu Biyu, E-mail: maofeng@suibe.edu.cn

\section{ARTICLE INFORMATION ABSTRACT}

Received: February 08, 2021

Accepted: March 14, 2021

Volume: 3

Issue: 3

DOI: $10.32996 / j$ jeltal.2021.3.3.1

\section{KEYWORDS}

Complex Dynamic System Theory, Compilation of College English textbooks, Big data
This paper finds that there are six problems in the compilation. Because of the complexity of teaching and learning materials and the dynamic progress of language learning, the nature of English teaching and learning materials is bound to turn from a learning tool to learning resources. Thus, this research, from the perspective of Complex Dynamic System Theory, attempts to develop big data-based College English learning materials with digital, individual and multi-dimensional characteristics by three paths: the establishment of big data-based English learning behaviors index system, the development of big data-based College English learning materials and the application of big data-based College English learning materials. This paper will explore a new way of developing China's College English learning materials and improving and optimising the compilation and development of College English learning materials in China.

\section{Problems of College English Textbooks Compilation}

In China, most scholars discuss about the textbooks that they have participated in compiling, including the introduction of the features of textbooks and compiling ideas, the revision instructions and so on. Most other researchers also evaluate textbooks via teachers' and students' questionnaires or according to their teaching experience. Many scholars talk to themselves, and mutual recognition is not high. Few research papers on College English textbooks discuss the theme with unique visions and new technology backgrounds. Likewise, few scholars can explore the research and development path of college students' English learning ability effectively according to China's national conditions and the needs of the new era. The following problems still exist in the compilation of College English textbooks:

1) The conflict between globalized consciousness and national identity. There is a serious imbalance between Chinese culture and western culture in the textbooks. The implicit ideology and cultural orientation in the textbooks are problematic. The textbooks generally guide students to accept the western ideas, values and lifestyles of consumption culture, and fail to express the traditional knowledge of Chinese local culture.

2) The conflict between basic education and general education. The compilation of textbooks still focuses on the basic English education and lacks general education. With the deepening of the popularization of English education in China, students have completed the basic English education before they go to college. It is no longer appropriate for them to continue to learn basic English after they go to college.

3) The conflict between traditional forms and application of science and technology. The main carrier of textbooks is paper books, which have a single form. They cannot be updated at any time and cause a waste of resources due to the low utilization rate of textbooks.

K C AL-KINDI CENTER

R D FOR RESEARCH AND DEVELOPMENT Your gateway to world-class research

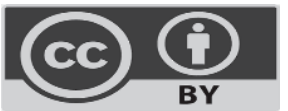

Published by Al-Kindi Center for Research and Development. Copyright (c) the author(s). This open access article is distributed under a Creative Commons Attribution (CC-BY) 4.0 license 
4) The conflict between exam-oriented education and quality-oriented education. Under the influence of CET-4 and CET-6, the textbooks are compiled as exam-oriented education services, which lack comprehensiveness and cause students to learn English passively.

5) The conflict between wholeness and individuality. College English textbooks are often written for the whole students, and college students cannot make an individualized choice.

6) The conflict between single capacity and comprehensive development. The compilation of College English textbooks is still dominated by English reading textbooks, which is relatively simple and lacks comprehensive listening and speaking materials. Listening and speaking materials are also mainly daily dialogues, with few coherent listening and speaking exercises.

Based on the above conflicts, we might as well change the train of thought. Perhaps traditional textbooks have been unable to meet the needs of various types and learning levels. What modern college students need is not some effective learning methods suitable for everyone, but a set of basic principles to help them build a classroom environment suitable for actual local needs. Professor Marjolijn Verspoor (2017:159) of the University of Groningen in the Netherlands points out that "The task of a teacher is not teaching itself, but to create a favorable environment in which the individual's best learning path can be realized". Therefore, based on the Complex Dynamic System Theory, this research takes big data as the new perspective to develop China's College English teaching and learning materials, and explores a way of the research and develops College English textbooks with big data that meets the needs of modern college students.

\section{Prospects of College English Textbooks Compilation}

Education is the most complex problem globally, so it needs to be understood in a complex way of thinking to achieve a breakthrough. The thought of Complex System breaks through the traditional simplified and linear thinking paradigm, focusing on the connection and integrity of things. The Complex Dynamic System Theory regards language as a complex, dynamic and systematic whole with self-organization, adaptability and openness (De Bot et al. 2007). Language teaching from the perspective of Complex Dynamic Systems does not advocate a single teaching method, nor only focuses on the progress of a single direction, but emphasizes more on the dynamic, complex and overall construction of language competence. (Zheng Yongyan, 2019) The scientific content arrangement is closely related to the teaching quality and students' language ability.

First of all, the content of the teaching and learning materials is complex. Textbook compliers or editors need to consider not only teachers, but also students, as well as national policies, cultural literacy and social needs. Secondly, the content of the teaching and learning materials is dynamic. The users of textbooks (each student or individual teacher) will have different demands for learning content under the influence of teaching resources, modern teaching equipment, cultural environment, social environment and other factors. In addition, the learning process is a dynamic process. Each student has different learning progress due to different learning styles, motivations, interests or strategies. Therefore, traditional textbooks can neither provide support for the developing digital, personalized and multi-dimensional teaching, nor meet the needs of multi-types and multilevel learning. In the era of big data, corpus data is characterized by complexity, dynamicity, authenticity, universality, historicity, interdiscipline, omnimedia and barrier-free (Zheng Tongtao \& Zeng Xiaoyan, 2016), which can provide new ideas for the research and development of College English textbookls. Therefore, in order to improve and optimize the compilation and development of China's College English textbooks, a practical implementation path can be formulated based on the development principles in combination with the characteristics of the era of big data corpus.

\subsection{Development Principles}

The development of big data-based College English teaching and learning materials is in line with the development of the new era, the progress of science and technology and the needs of the society, which has three characteristics: digitalized, Individualized and multi-dimensional.

\section{(1) Digitalized}

Information age provides humans with the broadest teaching resources, teaching materials of corpora data sources, which include written corpora, such as newspapers, magazines, news, novels, letters, diaries, brochures and others, and spoken corpora, such as broadcast, meetings, interviews, debate, preaching, talking face to face, telephone conversation, public discussion and so on. From the perspective of big data, teaching resources adopt more extensive and diverse information technologies, using data mining tools to transform data into knowledge, which provides broad support for foreign language teaching resources in China.

\section{(2) Individualized}

Teaching resources from big data can provide personalized teaching resources for learners with different backgrounds. Big data mining tools are used to analyze learners' learning behaviors. Learners' expectations and applications are counted according to the data to develop teaching and learning materials suitable for their use. Based on the analysis of learning behavior, the needs of teaching and learning materials can be investigated; the teaching objectives and learning objectives can be decomposed, and 
then the contents of teaching and learning materials can be selected and supplemented. In addition, based on complex and dynamic data, from the perspective of big data, users can choose teaching resources according to their actual needs and adopt different media means for learning, so as to achieve better learning results.

\section{(3) Multi-dimensional}

Big data can make the language appear in an encyclopedia, which contains language products of various communication occasions such as environment, society and nature. Based on the teaching resources developed by English teaching and learning materials with big data, in addition to the text resources development, it will also be combined with the image, video, sound and other information, to provide multimodal language input for learners. By investigating the learners' multi-modular cognitive pattern, big data learning materials can help learners' language learning or acquisition, understand the characteristics of the regular pattern of language development, and improve the ability of language.

\subsection{Implementation Paths}

The development of big data-based College English learning materials will be divided into three steps. First, combine computer technology and big data analysis step by step. Second, integrate personalized design and language acquisition rules with a unique and novel way. Third, develop new College English textbooks that meet the needs of times and students' requirements.

\section{(1) Construction of big data based English learning behavior indicator system platform}

Combined with the big data platform, the index system of college students' English learning behavior can be constructed. The interrelated and independent educational data are sorted out and integrated to predict students' English learning behavior, so as to comprehensively understand and predict students' learning behavior at school. The data sources of students' learning behaviors can be accessed through educational administration scores, English scores in College Entrance Examination, book borrowing records, competition awards, and student questionnaires. Through the questionnaire survey, the initiative of learning English and dynamic performance of related students can be understood. According to school's data management platform, English credits and academic point's average and classification of students can be revealed. Through the number of English books borrowed, and the frequency of going to library, and the times of language competition winning, learning results can be associated with it, which is helpful to construct learners' portrait. These data can accurately map the characteristics of college students' English learning behavior, contain students' behaviour rules, and provide English learning behavior prediction for different kinds of students by analyzing the data.

\section{(2) Development of big data-based English teaching and learning materials}

Big data-based English textbooks are divided into big data-based instructional materials and learning materials. Big data-based Instructional materials are small in scale and aim to enable students to narrow down the learning content and learn English in limited classroom time through organized listening, speaking, reading and writing practice, observation, discussion and reflection. Big data-based learning materials refer to a large amount of real and natural language corpus collected outside the teaching field, which is relatively large and can be used by teachers in designing tasks and make students in extension-based learning.

Through measurement, data collection, analysis and reporting learners and their environmental data, as well as learners' anticipation and application, the needs of teaching and learning materials can be investigated and the teaching goals and learning goals can be broken down based on learners' learning behavior analysis. By considering the macro factors, such as national policy, social requirements, local culture and so on, it is possible to research and develop big data-based English textbooks suitable for learners. Traditional paper English textbooks have a complete knowledge system and practical content. However, the content capacity of paper textbooks is relatively limited. Generally speaking, a unit can only cover three articles at most, which is far from enough to meet the reading capacity of the language. The e-teaching platform based on the big data teaching and learning materials has various forms and large storage capacity, creating teaching forms with the advantages of multimedia integration, man-machine interaction, diversity, portability, which can effectively improve the learning efficiency. The e-teaching system of big data-based teaching and learning materials appears in front of students in the role of learning companion and mentor, which overcomes the space-time limitation of teacher-student interaction. The system can track students' learning status through "push", "remind" and other ways, to judge, encourage and guide students' learning. Through human-computer interaction to guide students to study autonomously, the educational pursuit of "letting students be the master of learning" is truly realized. The electronic system platform of big data-based English teaching and learning materials can keep learners' learning records, and also provide the communication area or comment board for learners to reflect, interact and discuss, so as to enrich the user's experience, enhance his interest, interaction and competitiveness of learning.

\section{(3) Application of big data public English teaching and learning materials}

The use of College English textbooks based on big data in class is characterized by data-driven teaching with students as the main body, autonomous learning and practice. In class, task-driven teaching is adopted. Tasks are set in class to let students read the mini-texts prepared by the teacher in advance within the prescribed time, and then discuss, summarize and practice by 
themselves. In order to fully mobilize the enthusiasm of students, teachers should pay attention to the fact that each group participating in the discussion is composed of students at all different levels, which aims to expect students with better skills to help weaker students and ensures that every student can actively participate. Teachers are not only the executors of teaching and learning materials, but also the maintainers and revisers of teaching and learning materials. They adjust the teaching plans according to the constantly changing behaviors, learning interests, learning needs and learning strategies of learners, and make a choice or supplement of the contents of textbooks on the open big data-based teaching platform.

The big data-based learning materials can choose the corpus in the market, such as COCA and iWeb. COCA and iWeb corpora are composed of about 100 million corpora, covering five major categories: spoken language, novels, popular magazines, newspapers, and academic journals. Whether at COCA or iWeb, students can create a "virtual corpus" -- a personalized corpus. In just four or five seconds, students can build a "virtual corpus" that can be based on anything from chocolate to basketball, form solar energy to investing as well as Buddhism. Students can choose appropriate materials according to their own learning interests, and learning needs to independently complete the established learning objectives. The era of big data has brought abundant teaching resources, providing real corpus, the most extensive topics, dynamic communication process, real language combination series, and integrated communication records of in-class and out-of-class learning (Zheng Tongtao, 2016). Therefore, the research and development of big data-based learning materials also need to develop multi-level flexible and dynamic learning materials, such as audio, video, animation, and so on, to maximize the language learning effect.

\section{Conclusion}

China is experiencing a strategic transformation from a large country to a powerful country in foreign languages education (Shen Qi, 2019). Textbooks are the means to realize the teaching goal. The final purpose of College English textbooks is to guide students to learn. Effective foreign language teaching can provide a suitable environment to help learners find the best individual learning path based on the overall language resources exploration, discovery, restructuring and innovation. (Zheng Yongyan, 2019). From the perspective of Complex Dynamic System Theory, the research, with the development and changes of times, has developed new big data-based English teaching and learning materials with digitalized, personalized and multidimensional characteristics, providing new ideas for China's College English teaching and learning materials development to better cultivate English talents in China.

Funding: This research was funded by The National Social Science Fund of China (17WYS003) and East China University of Science and Technology (NO.80222301901001).

Acknowledgements: This paper would like to thank the following funding sources : National Social Science Project "Chinese Academic Translation Project: Jiangnan Landscape Theory" supported by National Office of Philosophy and Social Sciences (17WYS003) and Research Project on the Reform of Undergraduate Teaching Methods: "Study on the Construction of College English Teaching Case Bank and Application of Classroom Teaching" supported by East China University of Science and Technology (NO.80222301901001) .

Conflicts of Interest: The authors declare no conflict of interest.

\section{Reference}

[1] De Bot, K., \& Larsen-Freeman, D. (2011). Researching second language development from a dynamic systems theory perspective. In $A$ dynamic approach to second language development (pp. 5-24). John Benjamins

[2] De Bot, K., Lowie, W., \& Verspoor, M. (2007). A dynamic systems theory approach to second language acquisition. Bilingualism, $10(1), 7$.

[3] Shen J. (2019). 70 years of foreign language education planning of China: paradigm changes and strategic shifts. Journal of Xinjiang Normal University (Edition of Philosophy and Social Sciences), (05),68-77.

[4] Zheng T. T. \& Zeng X. Y. (2016). Study on development of Chinese country-specific teaching materials based on big data. Overseas Chinese Education, (03),291-302.

[5] Zheng Y. Y. (2019). The CDST perspective on effective foreign language teaching. Contemporary Foreign Languages Studies, (05), 12-16+49. 